\title{
Experiential Learning for Psychomotor Skills Development of Emergency Medical Services (EMS) Students: An Action Research
}

\author{
Daifallah Alrazeeni (D) \\ Ahtisham Younas (D) ${ }^{2,3}$ \\ Subia Parveen Rasheed ${ }^{4}$ \\ 'Department of EMS, PSCEMS, King Saud \\ University (KSU), Riyadh, Saudi Arabia; \\ ${ }^{2}$ Memorial University of Newfoundland, \\ St John's, Canada; ${ }^{3}$ Swat College of \\ Nursing, Mingora, Swat, Pakistan; ${ }^{4}$ Shifa \\ College of Nursing, Islamabad, Pakistan
}

Correspondence: Daifallah Alrazeeni Department of EMS, PSCEMS, King Saud University (KSU), Riyadh, Saudi Arabia Email dalrazeeni@ksu.edu.sa
Background: Experiential learning is useful for fostering the development of a wide range of clinical and practical skills. This study aimed to determine the usefulness of experiential learning for psychomotor skills development of emergency medical services (EMS) students. Methods: An action research approach was used because it is useful for linking theory with action and practice. The Field Internship Student Data Acquisition Project (FISDAP) tool was used to assess and monitor students' performance and competencies achievement in psychomotor skills. The study was conducted at Prince Sultan College for Emergency Medical Services (PSCEMS), King Saud University (KSU). Skills performance of 71 EMS students were analysed in the experiential learning implemented throughout the curriculum over 3 years.

Results: The finding indicates that the students' skills performance falls below the minimum requirement during the clinical practicum and significantly improves during the time of internship period. The overall success rate ranges between $26.58 \%$ and $35.74 \%$ across all the psychomotor skills, whereas during the internship year student's success rate ranges between $85.49 \%$ and $99.4 \%$ across all the psychomotor skills.

Conclusion: The findings of this study are promising and show that experiential learning is a useful and effective way to develop psychomotor skills and competencies in EMS students. Educators and policymakers can use the findings for strategizing policies for curriculum planning and development.

Keywords: experiential learning, psychomotor skills, emergency medical services, EMS, EMS students

\section{Introduction}

Working effectively and efficiently in today's complex and transforming health care and providing safe and ethical care requires continuous update of health professionals' skills and knowledge. Health-care professionals must focus on enhancing their knowledge and solving complex health illness problems and managing personal and organizational challenges affecting patient care. ${ }^{1,2}$ It is essential that educators prepare their students in health professions education for competent and clinical practice to meet the demands of contemporary health care systems. Therefore, teaching and learning must be tailored to meet the emerging demands of effective clinical practice. Experiential learning is essential for enhancing the practical and psychomotor skills development in health-care students because of the intricacy of health-illness phenomena and the uncertainties associated with health-care students. ${ }^{3,4}$ Experiential learning refers to 
learning by doing and entails hands on experiences. It combines teaching and learning strategies and activities targeting behavioral, perceptual, and cognitive domains. ${ }^{5}$ The three key aspects of experiential learning are "personal experience, reflection on the experience, and transformation of knowledge and meaning as a result of that experience"6 (p.3).

Kolb $^{5}$ elaborated the following essential characteristics of experiential learning: a) learning as a process involving derivation and formation of concepts and ideas and their development and refinement through experience, b) learning is a continuous process grounded in experience entailing testing and development of knowledge with experience, c) learning is a process of conflict resolution arising due to contrasting modes of learning, d) learning is an adaptation to social and physical learning environments, e) learning is a continuous process of transaction between an individual and their environment and f) learning is a process of knowledge creation entailing basic and advanced knowledge through interactions between personal and social aspects. ${ }^{5}$

In accordance with these characteristics, an array of teaching and learning strategies can be used under experiential teaching. Some of the commonly used strategies are simulation, case-based learning, project-based learning, web-based learning, group and peer learning, and reflection writing. ${ }^{7-10}$ All of the above teaching and learning strategies have been evaluated and tested across health professions education using various research methods to teach relational, ethical, and psychomotor skills. ${ }^{11-15}$ Ferro Allodola $^{16}$ conducted a systematic review to assess the effects of educational models based on experiential learning in university level continuing training of health-care professionals. They reviewed 47 studies from medicine, nursing and health professions education and noted the usefulness of experiential learning for teaching transcultural care, pre-emergency hospital care, empathy, interprofessional skills, and psychomotor skills. It was found that experiential learning was effective in enhancing clinical and practice-based skills and knowledge of practitioners and students. Given that experiential learning is useful for fostering the development of a range of clinical and practical skills, this paper focused on the use of experiential learning in teaching psychomotor skills.

\section{Purpose}

To determine the usefulness of experiential learning for psychomotor skills development of emergency medical services (EMS) students.

\section{Methods}

\section{Design}

An action research approach was used because it is useful for linking theory with action and practice. This approach was relevant because the research participants were directly involved in the planning and implementation of the experiential learning project. ${ }^{17}$ Their regular academic data entry is essential in the analysis of this research. Action research is also useful in educational settings to implement and evaluate changes in curricula. This project focused on implementing a new tool for improving student learning. The primary focus was on improving student competency in performing psychomotor skills and bringing about a change in their practice.

\section{Setting}

The study was conducted at the Prince Sultan College for Emergency Medical Services (PSCEMS), King Saud University (KSU). The PSCEMS was established to produce graduates with skills and competencies enabling them to provide emergency medical services of high quality through the educational environment supporting remarkable scientific research, continuing medical education, employment of modern technology and the optimal use of available resources, and effective partnerships.

\section{Sample and Sampling}

Skills performance information of 71 EMS students was used in the experiential learning implemented throughout the curriculum over 3 years. In each level or semester, students were required to successfully satisfy certain number of skills requirements according to the sequence of the requirements in the curriculum. This is an accumulative longitudinal collection of the selected EMS students' skills performance during all 5 clinical practice courses. This batch of EMS students graduated June 2019 and completed their internship year in July 2020. Students benefit from large number of in-field preceptors in EMS (26 stations each consist of 10 to 12 crew members) and inhospital clinicians and physicians. In the college, there are about 12 faculty members who evaluate and appraise students' performance.

\section{Description of the Experiential Learning Project}

The EMS program 3 years long staged process entailing the preparatory and the internships years. This complex 
program consists of: a) several general knowledge courses for health-care professionals such anatomy, physiology and pathophysiology and pharmacology, b) in depth core courses for emergency medical professionals such as patient assessment, medical emergencies, trauma emergencies, cardiology, critical care, clinical decision-making, and c) five field and clinical (CP 1-5) practice and a 12 month internship year of clinical practice. Most of these courses are taught through a combination of theoretical and experiential learning strategies for psychomotor skills development.

Tool and Process for Implementation: The main tool PSCEMS utilized for assurance of students' competencies attainment is FISDAP. It is an online software that is designed to create innovative solutions for teaching and learning of EMS and health-care education. "FISDAP" stands for: The Field Internship Student Data Acquisition Project. FISDAP was built on the idea of shifting the attention from hours-based requirements to skills- and competencies-based requirements. The EMS program curriculum includes a list of skills goals students are required to complete before they could graduate. EMS programs educators need a way to track the specific skills performed and patient types encountered during student internships and clinical practice. It is a web-based tracking system that would help educators to document and report such information. The database not only gave educators the documentation they needed for accreditation but it is a powerful resource for EMS educational research.

With the acknowledgement that prior to the implementation of FISDAP, PSCEMS used a manual registry book for the students to fill on every scheduled shift of training to track their performance that was reviewed by the course instructor. This manual registry book written documents resulted in tremendous amounts of written data that required a great effort in following up and tracking and assessing students' skills performance and the statistical and educational analysis of student performance.

FISDAP is utilized at PSCEMS in tracking the students' performance of successful skills in the practical learning in simulation labs. According to the scheduled skills lab for certain skills and certain patients, access is opened for students to document the skills practiced on the simulated patients in labs with instructors. In addition, PSCEMS utilizes FISDAP for five different clinical practice and internship courses (two in the EMS field and three in the specialized hospitals) to track students' successful skills performance in EMS field and clinical settings.
Similarly, according to the scheduled EMS and clinical shifts, access is open for students to document the skills performed on the actual patients with preceptors. Moreover, various types of medical and traumatic patients are specified for the students to treat or attend their care. During the internship list of skills to each department are specified to allow students to perform and learn.

Throughout various academic activities, FISDAP is a beneficial electronic tool that helps in measuring experiential learning of students, stimulating their critical thinking, enabling students to document skill performance with different patients, organizing complex shift schedules, and collecting large amount of data generated from many students in multi-educational programs.

FISDAP is an educational tool to track students skills that documents student learning, reports achievement and growth. It helps students with performance reports. After the patient contact, students document their experience on the FISDAP website. Individuals involved in the learning process including students, instructors, preceptors, medical directors can play a role in monitoring and evaluating the students' experiential learning and can quickly and easily generate comprehensive reports. The evaluation helps to track student performance, prompt preceptors to give students feedback, and promote self-reflection and selfevaluation among students.

The significance of the software FISDAP as an effective educational tool comes from the concept of shifting great part of the education operations from manual educational system to an electronic one. Students training scheduling, case reporting, skills tracking, students' performance assessment, analysis and feedback all become electronic on FISDAP.

Psychomotor Skills/Goals for Students: In total, students performed and were evaluated for the following skills generated from FISDAP: airway management, health assessment (ten systems), medication administration, intravenous insertion, live intubation, endotracheal intubation, ventilations.

\section{Research Action Implementation}

By referring to the comments included in the evaluation reports of the clinical practice courses provided by students and instructors in the college, several negative attributes were identified that might cause the low performance of students during the practice. They include: irregular, unstable and inconsistent preceptorship, insufficient practice hours, insufficient documentation review, inconsistent documentation method, inflexible training schedules, and busy and crowded 
field work with other trainees, inadequate practice lead-role opportunities and inconsistent evaluation method by preceptors. Therefore, an interventional action for improvement was taken prior to the beginning of the internship year. The action targeted several areas. First, setting preceptorship requirements which included a preceptor orientation training course (to explain their roles and responsibilities, follow up with students, assessment methods) and a regular, stable and consistent preceptorship program with students. Second, setting training sites requirements which included: sufficient practice hours weekly, thorough training schedule, and avoid crowded field work with other trainees. Third, setting documentation requirements which include: setting documentation requirements and thorough documentation review and discussion sessions. Fourth, skills performance enhancement by allowing adequate practice lead opportunities, skills attainment checklist and ongoing skills performance reports review. Fifth, students' cooperation and involvement which include: conducting students' orientation training course (to explain their roles and responsibilities, follow up with preceptors, assessment methods, required skills and the appropriate documentation methods) (Figure 1).

\section{Students' Involvement and Cooperation}

Within in the college program, senior students are asked for their opinions about the clinical practice places they find as best learning environment for certain skills and the most needed skills and competencies in clinical setting or in EMS field. Moreover, students give their feedback about a variety of aspects in clinical practice in a regular basis at the end of every semester. Feedback regarding the placement, preceptors' guidance, obstacles, and skills attainment challenges. Their comments are taken in a positive manner into the curriculum and therefore into courses specifications.

As the main factor to succeed in the interventional action is the students' cooperation in data entries, therefore an important step was taken to involve the students to play part in fulfilling their academic requirement and document the data according to the explanations they receive prior the beginning of the internship year. This interventional action motivates students to be more critical and focused on the quality of data fed in FISDAP, especially narrative writing for every patient they take care of.

\section{Ethical Considerations}

The ethical approval for this research (No. 21/0290/IRB) was obtained from the Institutional Review Board (IRB) at King Saud University (KSU) based on the assurance that the researchers abide by the rules and regulations of the kingdom of Saudi Arabia and the research policies and procedures of the IRB-KSU and remain committed to them. That includes applying informed consent guidelines and

\begin{tabular}{|c|c|}
\hline \multicolumn{2}{|c|}{ Action Conducted } \\
\hline \multicolumn{2}{|c|}{ For Experiential Learning development for Psychomotor Skills of Emergency Medical Services (EMS) Students } \\
\hline 1 - 5 Clinical Practice credits courses & 12 months Internship year \\
\hline \multicolumn{2}{|c|}{ Pre-intervention students' performance } \\
\hline \multicolumn{2}{|c|}{ Analysis of Negative Attributes } \\
\hline $\begin{array}{ll}\text { - } & \text { Irregular, Unstable and Inconsistent preceptorship } \\
\text { - } & \text { Insufficient practice hours } \\
\text { - } & \text { Insufficient documentation review } \\
\text { - } & \text { Inconstant documentation method }\end{array}$ & $\begin{array}{ll}\text { - } & \text { Inflexible training schedules } \\
\text { - } & \text { Busy and crowded field work with other trainees } \\
\text { - } & \text { Inadequate practice lead opportunities } \\
\text { - } \quad \text { Inconstant evaluation method. }\end{array}$ \\
\hline \multicolumn{2}{|c|}{ Interventional Action for improvement } \\
\hline $\begin{array}{l}\text { Preceptorship Requirement: } \\
\text { - } \quad \text { Conduct a preceptor orientation training course (to explain } \\
\text { their roles and responsibilities, follow up with students, } \\
\text { evaluation methods) } \\
\text { - } \quad \text { Implement a Regular, Stable and Consistent Preceptorship } \\
\text { with students } \\
\text { Training sites Requirements: } \\
\text { - } \quad \text { Sufficient practice hours } \\
\text { - } \quad \text { Thorough training schedule } \\
\text { - } \quad \text { Avoid crowded field work with other trainees } \\
\text { Documentation Requirements: } \\
\text { - } \quad \text { Setting documentation requirements } \\
\text { - } \quad \text { Thorough documentation review and discussion sessions }\end{array}$ & $\begin{array}{l}\text { Skills Performance: } \\
\text { - } \quad \text { Adequate practice lead opportunities } \\
\text { - } \quad \text { Skills attainment check list } \\
\text { Students cooperation and involvement: } \\
\text { - } \quad \text { Conduct a students' orientation training course (to explain their roles } \\
\text { and responsibilities, follow up with preceptors, evaluation methods, } \\
\text { required skills and the appropriate documentation methods) } \\
\text { - Senior students for their opinions about the clinical practice and the } \\
\text { needed skills and competencies in clinical setting or in EMS field. } \\
\text { - Students' feedback about verity of aspects in clinical practice. }\end{array}$ \\
\hline
\end{tabular}

Figure I Action for experiential learning development for psychomotor skills of emergency medical services (EMS) students. 
Table I Student Performance in Clinical Practice (CP I-5) Before the Internship Year

\begin{tabular}{|c|c|c|c|c|}
\hline \multicolumn{2}{|l|}{ SKILLS } & $\begin{array}{l}\text { Minimum Required Skills } \\
\text { Performance }\end{array}$ & Average Skills Achievement & $\begin{array}{l}\text { Overall Success } \\
\text { Rate }\end{array}$ \\
\hline \multicolumn{2}{|c|}{ Airway management } & 20 & 6.25 & $26.58 \%$ \\
\hline \multirow{10}{*}{$\begin{array}{l}\text { HEALTH } \\
\text { ASSESSMENT }\end{array}$} & Abdominal & 15 & 5.64 & \multirow[t]{10}{*}{$44.55 \%$} \\
\hline & CVA & 0 & N/A & \\
\hline & Cardiac & 0 & 5.45 & \\
\hline & $\begin{array}{l}\text { Cardiac } \\
\text { Arrest }\end{array}$ & 0 & 1.9 & \\
\hline & Medical & 75 & 26.29 & \\
\hline & Neurological & 0 & 3.37 & \\
\hline & Obstetrics & 5 & 0.4 & \\
\hline & Psychiatric & 15 & 7.78 & \\
\hline & Respiratory & 15 & 10.79 & \\
\hline & Trauma & 20 & 14.86 & \\
\hline \multicolumn{2}{|c|}{ Medication Administration } & 20 & 14.58 & \multirow[t]{5}{*}{$35.74 \%$} \\
\hline \multicolumn{2}{|c|}{ Intravenous Insertion } & 20 & 11.9 & \\
\hline \multicolumn{2}{|l|}{ Live Intubation } & 5 & 0.49 & \\
\hline \multicolumn{2}{|c|}{ Endotracheal Intubation } & 5 & 0.49 & \\
\hline \multicolumn{2}{|l|}{ Ventilations } & 15 & 7.8 & \\
\hline
\end{tabular}

regulations besides protecting the identities and information related to any student, therefore, no individual privacy could be compromised. Any participation from the EMS students in any part of this research project was voluntary and they had the right to refuse or withdraw from the participation at any time. Moreover, data extracted from FISDAP database that would be necessary in the analysis to interpret, replicate, and build upon the findings reported in this study is available from the corresponding author on reasonable request.

\section{Results}

\section{Demographic Information}

The students included in the study is one-batch from PSCEMS. They started EMS program in 2017- to-2019. After completion of the study plan, they joined the internship year for 12 months. Skills performance data of all 71 male students were reviewed (no female students in the program). Students' ages ranged from 19 to 20 years by their start in the program and 23-24 years when they graduate from the program.

\section{Psychomotor Skills and Student Performance}

Students' skills and performance were analyzed at two different time periods. First, during the program when students were required to perform skills as requirement of the credit registered clinical practice courses CP 1 to CP 5. Second, assessment was undertaken at the completion of the 12 months internship year. The scoring system used is the average number of successful skills achieved by students as a whole compared to the number of successful skills required.

The finding indicates that students' skills performance fall below the minimum required skills performance. The overall success rate across the three skills categories (Airway management, Health Assessment, and the five core EMS students' skills) was $26.58 \%, 44.55 \%$, and $35.74 \%$, respectively. While the performance of medication administration reported to be the highest performed skills (14.58), students scored the lowest performance in Obstetrics (0.4) (Table 1). On the other hand, overall and 
Table 2 Student Performance in Clinical Practice (CP I-5) and the Internship Year

\begin{tabular}{|c|c|c|c|c|}
\hline \multicolumn{2}{|l|}{ SKILLS } & $\begin{array}{l}\text { Minimum Required Skills } \\
\text { Performance }\end{array}$ & Average Skills Achievement & $\begin{array}{l}\text { Overall Success } \\
\text { Rate }\end{array}$ \\
\hline \multicolumn{2}{|c|}{ Airway Management } & 20 & 38.37 & $85.49 \%$ \\
\hline \multirow{10}{*}{$\begin{array}{l}\text { HEALTH } \\
\text { ASSESSMENT }\end{array}$} & Abdominal & 15 & 20.51 & \multirow[t]{10}{*}{$99.93 \%$} \\
\hline & CVA & 0 & $\mathrm{~N} / \mathrm{A}$ & \\
\hline & Cardiac & 0 & 14.46 & \\
\hline & Cardiac Arrest & 0 & 5.9 & \\
\hline & Medical & 75 & 84.2 & \\
\hline & Neurological & 0 & 6.94 & \\
\hline & Obstetrics & 5 & 6.07 & \\
\hline & Psychiatric & 15 & 17.99 & \\
\hline & Respiratory & 15 & 23.2 & \\
\hline & Trauma & 20 & 34.01 & \\
\hline \multicolumn{2}{|c|}{ Medication Administration } & 20 & 50.96 & \multirow[t]{5}{*}{$99.46 \%$} \\
\hline \multicolumn{2}{|c|}{ Intravenous Insertion } & 20 & 37.42 & \\
\hline \multicolumn{2}{|l|}{ Live Intubation } & 5 & 12.89 & \\
\hline \multicolumn{2}{|c|}{ Endotracheal Intubation } & 5 & 12.89 & \\
\hline \multicolumn{2}{|l|}{ Ventilations } & 15 & 21.58 & \\
\hline
\end{tabular}

by the end of the EMS program and after the internship year, student success rate in the skills categories ranged from $85.49 \%$ to $99.4 \%$ across all the psychomotor skills. The average achieving score was highest for medication administration, health assessment, and airway management skills. Among the health assessment skills, the highest average skills achievement was for medical (84.2) and psychiatric assessment (17.99) (Table 2).

\section{Discussion}

This study determined the usefulness of experiential learning for psychomotor skills development of EMS students in PSCEMS Saudi Arabia. Unlike the old manual written documentation system, FISDAP tool was used in EMS education for electronically documenting, tracking, and assessing students' skills performance. It also allowed for greater involvement of students in their learning and evaluation. In this study, the trustworthiness of the students input to FISDAP is granted. However, all the skills assessment form entries were validated by the preceptor and the clinical instructors/coordinators. The criteria were well established for passing the skills and number of times the specific skills should be performed. The time duration of the five clinical practice courses was one day in a week for $9 \mathrm{hrs}$./day. Whereas during the internship year, the time duration was five days in a week for $9 \mathrm{hrs}$./day.

This study mainly focused on most essential psychomotor skills such as health assessment, airway management, intravenous insertion, medication administration, endotracheal intubation, and ventilation. Therefore, to integrate theoretical knowledge into practice, a wide variety of clinical placements were utilized such as in-field (Ambulance-based training), hospital (Emergency Room (ER), Operation Room (OR), Intensive Care Unit (ICU) and high-fidelity simulation labs). The findings of this study are promising and show that experiential learning using FISDAP is useful and effective way to develop psychomotor skills and competencies in EMS students. These findings are consistent with previous studies $^{12}$ that experiential learning was effective strategy for clinical skill competency development in nursing education. It helped students to gain mastery in history taking and physical examination. Consistently, experiential learning in 
ambulance services in the undergraduate nursing program in prehospital emergency care was successful in development of student's comprehensive care approach, clinical reasoning, reflective practice, and self-awareness. ${ }^{18}$ It also promotes the students' interaction and communication skills in interdisciplinary health-care teams. ${ }^{13,16}$

The students' performance in psychomotor skills was different between the clinical practice during the 3 years program and during the one-year internship period. The finding indicates that the students' skills performance fall below the minimum requirement during the clinical practice and significantly improved during the time of internship period. The overall success rate range between $26.58 \%$, to $35.74 \%$ across all the psychomotor skills in clinical practice. However, during the internship year student's success rate range between $85.49 \%$ and $99.4 \%$ across all the psychomotor skills. These findings are consistent with the previous study ${ }^{19}$ that internship year brings more opportunity and time for the students to be engaged in hands on practice and it showed students improvement in most of clinical skills over time. Moreover, it is noted that experiential learning during internship improves students' interpersonal skills, self confidence, and their psychomotor skills competencies level. ${ }^{20}$ Experiential learning approach ultimately prepares EMS students for the transition to work life. ${ }^{21}$ Moreover, the applied intervention motivated students to be more critical and focused on the quality of data fed in FISDAP, such as initial patient assessment, detailed medical or trauma physical examination, patients medical history taking, vital signs obtaining, medical impression about patient's condition, provided treatment and reassessment of the patients were critically analysed and evaluated in each FISDAP report.

It is important to clarify that it is not necessarily that the time duration was the only factor for the students to score higher over the 12 months internship because the CP 1-5 was spread over 3 years' time and covered exact departments of training placements. Moreover, the interventions applied played a major factor for the students to achieve the exact number and quality of skills performance intended in the training. FISDAP tool was a great assistant to achieve the intended outcomes of the intervention.

There were certain challenges during the practicum period of the program, which could have affected students' performance. Those are time constraints, limited number of cases overall in some days of practice, presence of students from other educational institutions in the practice and limited number of opportunities to perform certain rare skills such as endotracheal intubation. These challenges were overcome by providing the students the opportunity to practice these skills in high fidelity simulation labs. In simulation labs students can practice without the fear of any harm to the patients. Moreover, students had the opportunity to perform, reflect, discuss with each other, and provide feedback. It is suggested that simulation-based experiential learning is helpful is developing medical students' professionalism, ethical and cultural competence without jeopardizing the safety of the patients. ${ }^{11,14}$ Also, the students were able to practice intubation in the OR if they did not get the opportunity in the ambulance services. Moreover, Internship year gave the students the time and opportunity to practice and gain competencies in required skills which they were unable to achieve during the clinical practicum period. It is important that different variety of teaching strategies and clinical placements are offered, and the time duration of those clinical practice is important for the preparedness of EMS students for professional working life., 7,22

Paramedics are an important part of health-care system and specifically in the prehospital care. Therefore, it is essential to provide quality-based education and give them the required knowledge, skills, and competencies to be able to provide safe, efficient, and ethical care to the wide variety of patients group. Competency-based teaching approach is essential for EMS education and thus efforts should be directed towards the development of this area for the better progress of the discipline in health care. ${ }^{23}$ A scoping review by Alshammari et $\mathrm{al}^{24}$ proposed five core competencies for EMS education. These are communication, clinical skills, teamwork, critical thinking and decision-making, and professional behavior. In a Delphi study from Saudi Arabia, these competencies emerged for EMS education, such as legal and ethical practices, safety procedures, respect and nondiscrimination, decision-making and critical thinking and clinical practice. $^{25}$ Therefore, the findings of this study will be useful for educational institutions in planning and developing strategies to facilitate psychomotor skills and competencies development in EMS education. It would also help educators and educational institution to plan pedagogies focusing on experiential learning. FISDAP is a new tool in EMS education in Saudi Arabia and obviously may have many challenges. Faculty members, staff and student training is crucial to use the tool effectively and efficiently. FISDAP could also be costly, and every institution might not be able to afford it. Therefore, further studies are needed to find out the perspectives and challenges of using FISDAP from both students and faculty perspectives. Other research endeavors 
can focus on the comparison between the post-FISDAP with earlier pre-FISDAP data.

\section{Limitations}

There were some limitations to this study as the sample size was small and this study was only conducted in one university in Saudi Arabia, therefore the generalizability of the findings may be limited. Further research is needed to explore the concept from larger population and different educational institutions. Another important area of study is to measure the achievement of psychomotor skills performed in the simulation lab verses in the clinical practice.

\section{Conclusions}

Experiential learning through advanced software such as FISDAP is a successful approach in developing the psychomotor skills in EMS education. It is important to offer the students variety of clinical practice settings such as simulation labs, ambulance services and hospital settings. The findings of this study provide valuable information on the usefulness of experiential learning in EMS education, so it is suggested that educators and policymakers to consider this approach while strategizing policies for curriculum planning and development. Further research in needed to explore experiential learning for psychomotor skills development in different EMS institutions and the challenges of FISDAP tool.

\section{Data Sharing Statement}

The data are available for use from the corresponding author upon reasonable request.

\section{Ethics Approval and Consent to Participate}

The research was carried out carried out in accordance with Ethics of IRB-KSU guidelines and requirements. An informed consent was obtained from students and according to IRB guidelines and regulations. Protecting the privacy, identities and information related to any student was assured. Moreover, data that would be necessary in the analysis to interpret, replicate, and build upon the findings reported is remaining available from the corresponding author on reasonable request.

\section{Consent for Publication}

The participants granted the permission to publish the findings of this study.

\section{Acknowledgments}

This work was supported by Prince Sultan Bin Abdul-Aziz College for Emergency Medical (PSCEMS) Services Research Center, Deanship of Scientific Research, King Saud University, Riyadh, Saudi Arabia. We would like to appreciate Field and clinical training unit at PSCEMS represented by Mr. S. Al Wahbi and Mr. J. Al Mansour for the efforts made to make the data available.

\section{Author Contributions}

All authors contributed to data analysis, drafting or revising the article, gave final approval of the version to be published, agreed to the submitted journal, and agreed to be accountable for all aspects of the work.

\section{Funding}

The researchers declare no funding for the research.

\section{Disclosure}

The authors report no conflicts of interest in this work.

\section{References}

1. Peterson C. Health professions education: a bridge to quality. Tar Heel Nurse. 2003.

2. Mann K, Gordon J, MacLeod A. Reflection and reflective practice in health professions education: a systematic review. Adv Heal Sci Educ. 2009;14:595-621. doi:10.1007/s10459-007-9090-2

3. Panwala T, Rajdev S, Mulla S, et al. A qualitative study on education leadership styles and teacher morale. PLoS Negl Trop Dis. 2017.

4. Ross LJ, Jennings PA, Gosling CMR, Williams B. Experiential education enhancing paramedic perspective and interpersonal communication with older patients: a controlled study 11 Medical and Health Sciences 1117 Public Health and Health Services. BMC Med Educ. 2018;18(1):1.

5. Kolb DA. Experiential Experience Learning Experience as the Source of Learning and Development. Experiential Learning: Experience as the Source of Learning and Development. FT press; 2015.

6. Burnard P. Teaching Interpersonal Skills: A Handbook of Experiential Learning for Health Professionals. Cardiff: University of Wales college of Medicine; 2013.

7. Chang YT, Tsai KC, Williams B. What are the educational and curriculum needs for emergency medical technicians in Taiwan? A scoping review. Adv Med Educ Pract. 2017;8:649-667. doi:10.2147/AMEP.S140839

8. Grace S, Innes E, Patton N, Stockhausen L. Ethical experiential learning in medical, nursing and allied health education: a narrative review. Nurse Educ Today. 2017;51:23-33. doi:10.1016/j. nedt.2016.12.024

9. Hills CM, Levett-Jones T, Lapkin S, Warren-Forward H. Generation $\mathrm{Y}$ health professional students' preferred teaching and learning approaches: a systematic review. Open J Occup Ther. 2017;5. doi:10.15453/2168-6408.1278

10. Smith Budhai S. Best Practices in Engaging Online Learners Through Active and Experiential Learning Strategies. Best Practices in Engaging Online Learners Through Active and Experiential Learning Strategies. Routledge; 2017. 
11. Logar T, Le P, Harrison JD, Glass M. Teaching corner: "first do no harm": teaching global health ethics to medical trainees through experiential learning. J Bioeth Inq. 2015;12:69-78. doi:10.1007/ s11673-014-9603-7

12. Hill B. Research into experiential learning in nurse education. $\mathrm{Br}$ J Nurs. 2017;26:932-938. doi:10.12968/bjon.2017.26.16.932

13. Barron D, Khosa D, Jones-Bitton A. Experiential learning in primary care: impact on veterinary students' communication confidence. $J$ Exp Educ. 2017;40(4):349-365.

14. Arias T, Coxon K. An experiential model of education introduced to improve the confidence of student midwives in undertaking second stage management of the perineum (SSMP). Midwifery. 2018;59:144-148. doi:10.1016/j.midw.2018.01.014

15. Birt J, Stromberga Z, Cowling M, Moro C. Mobile mixed reality for experiential learning and simulation in medical and health sciences education. Information. 2018;9(2):31.

16. Ferro Allodola V. The effects of educational models based on experiential learning in medical education: an international literature review. Riv Della Soc Ital di Pedagog Medica. 2014;14(1):23-49.

17. MacDonald C. Understanding participatory action research: a qualitative research methodology option. Can $J$ Action Res. 2012;13(2):34-50.

18. Melby V. Experiential learning in pre-hospital emergency care: a qualitative study. Nurse Educ Today. 2000;20:638-645. doi:10.1054/nedt.2000.0496

19. Alrazeeni DM. International internship experience for emergency medical service paramedic students. Saudi J Anaesth. 2018;12 (4):540-547.
20. Wongtongkam N, Brewster L. Effects of clinical placements on paramedic students' learning outcomes. Asia Pacific J Heal Manag. 2017;12:24-31. doi:10.24083/apjhm.v12i3.55

21. Lucas PV, McCall MJ, Eccleston C, et al. Prioritising the development of paramedic students' interpersonal skills. J Paramed Pract. 2015;5(2):35-41.

22. O'Brien K, Moore A, Hartley P, Dawson D. Lessons about work readiness from final year paramedic students in an Australian university. Australas J Paramed. 2013;10. doi:10.33151/ajp.10.4.52

23. Clements R, Mackenzie R. Competence in prehospital care: evolving concepts. Emerg Med J. 2005;22(7):516-519.

24. AlShammari T, Jennings PA, Williams B. Emergency medical services core competencies: a scoping review. Heal Prof Educ. 2018;4 (4):245-258

25. Alshammari T, Jennings PA, Williams B. Emergency medical services core competencies: a delphi study. Australas J Paramed. 2019;16.

26. Ferro Allodola V. The effects of educational models based on experiential learning in medical education: an international literature review. Tutor-Attualità, Propos e Ric per l'Educazione nelle Sci della Salut. 2014:23-49.

27. MacDonald C. Understanding participatory action research: a qualitative research methodology option. Can $J$ Action Res. 2012;13(2):34-50.
Journal of Multidisciplinary Healthcare

\section{Publish your work in this journal}

The Journal of Multidisciplinary Healthcare is an international, peerreviewed open-access journal that aims to represent and publish research in healthcare areas delivered by practitioners of different disciplines. This includes studies and reviews conducted by multidisciplinary teams as well as research which evaluates the results or conduct of such teams or healthcare processes in general. The journal

\section{Dovepress}

covers a very wide range of areas and welcomes submissions from practitioners at all levels, from all over the world. The manuscript management system is completely online and includes a very quick and fair peer-review system. Visit http://www.dovepress.com/testimonials. php to read real quotes from published authors. 